\title{
PIRÂMIDE DA PEDAGOGIA HACKER: DE SONHOS COLETIVOS A ENGAJAMENTOS REAIS
}

Karina Moreira Menezes Nelson De Luca Pretto ${ }^{(*)}$

\section{INTRODUÇÃO}

Em alguns contextos sociais, a palavra hacker já não assusta tanto quanto antigamente. Antes usada para se referir a criminosos digitais, agora tem sido apropriada em seu sentido originário para nominar pessoas criativas, com conhecimentos profundos em diversas áreas de conhecimento e que utilizam seus saberes para propor soluções criativas para problemas reais, através das tecnologias. Um diferencial dessa visão positiva do ser hacker está na percepção de que são pessoas orientadas por uma cultura da colaboração impulsionada pela partilha de saberes em comunidade tanto nas redes digitais quanto em espaços físicos. No que se refere especialmente aos espaços físicos, significativa parte destes espaços tem como diferencial a autogestão comunitária e voluntária, sem fins lucrativos, nos quais se desenvolvem projetos tecnológicos diversos. Investigamos a origem e o funcionamento de alguns desses espaços no Brasil a fim de compreender seu funcionamento e as práticas de seus participantes e encontramos pessoas interessadas em aprender e compartilhar o que aprendem colocando em evidência a dimensão educativa desses espaços. A partir de um estudo empírico, interpretamos esse conjunto de práticas pelo viés da educação, apontando para uma Pedagogia própria estruturada em engajamentos, através dos quais esses espaços físicos são criados e ampliados, constituindo-se como espaços mais permanentes ou mesmo tendo uma vida efêmera. Nos limites desse texto, apresentamos a Pirâmide da Pedagogia Hacker em Hackerspaces como caminho para a promoção de uma educação que valoriza o engajamento e a colaboração.

\section{TODO MUNDO PRECISA DE UM HACKER}

Em sua versão inglesa - "Everybody Needs a hacker" - essa frase aparece estampada em camisetas de desenvolvedores de softwares e ilustra a interdependência de toda a sociedade interconectada por meio das tecnologias informacionais. O desenvolvimento tecnológico se dá de forma tão acelerada e com tantas novidades, que é um desafio manter-se atualizado. Com a

\footnotetext{
${ }^{(*)}$ Karina M. Menezes. E-mail: karina.menezes@ufba.br.
}

Nelson Pretto. E-mail: nelson@ pretto.pro.br. 
convergência digital, os eletrônicos trazem embutidos uma diversidade de serviços exigentes de configurações específicas, cujas instruções nem sempre são compreendidas através da leitura dos manuais. O emaranhado de informações que surge a cada atualização tecnológica, bem como os potenciais problemas advindos das novas soluções na área, aumenta a procura por pessoas que compreendam as linguagens características dessas tecnologias. Portanto, se em nossas casas muitas vezes buscamos ajuda no trato cotidiano com as máquinas digitais - e esse "especialista" muitas vezes é alguém mais jovem e com mais traquejo com esses aparatos - o que dizer da necessidade de verdadeiros especialistas nas áreas tecnológicas?

Nesse contexto, o termo hacker se destaca contemporaneamente quando se procura por pessoas criativas e com conhecimentos tecnológicos especializados, capazes de solucionar desafios e realizar seu trabalho com paixão. Essas são algumas das características de um movimento que ficou conhecido como hackerismo e sua história contribui para o seu entendimento.

Originariamente, o verbo em inglês to hack significa "entalhar". Dentre estudantes do Instituto de Tecnologia de Massachusetts no final dos anos 1960 e anos 70, no Clube de Ferreomodelismo The Model Railroad (TRMC/MIT), o hacker era aquele que fazia entalhes criativos para criar locomotivas, tanto quanto aqueles que desmontavam centrais telefônicas velhas para usar peças no sistema elétrico dos trens em miniatura. O importante é que isso estivesse sendo feito com talento, beleza e criatividade. Com a popularização da comunicação interconectada e dos computadores pessoais, foram surgindo casos de jovens curiosos que desafiavam as regras e questionavam os monopólios de uso desses sistemas e, portanto, em nome da curiosidade, cometiam atos invasivos, considerados ilícitos, mesmo que esse ilícito nunca fosse usado para lesar quaisquer outras pessoas. Obviamente, havia outros que deliberadamente cometiam crimes usando seus conhecimentos, de modo que as fronteiras éticas nesses grupos se tornavam opacas para quem os observa de fora. Por isso, historicamente, a disputa de sentidos sobre a palavra hacker fez com que esses sujeitos fossem apontados como criminosos do mundo digital pela mídia de massa. Entre os anos 1980 e 1990, por exemplo, encontramos notícias e filmes retratando roubos digitais, caos da segurança social e apocalipses nucleares causados pela ação de hackers, reduzindo-os a vândalos (SEARA, 2001), realidade e ficção se encontravam na grande mídia, causando muito temor e pouco esclarecimento. Tudo isso levou à distorção na compreensão dos valores fundantes dessa cultura e ao apagamento das contribuições trazidas para a sociedade informacional, dentre as quais podemos citar o desenvolvimento de instruções para comunicação livre via internet, a disseminação de softwares livres e abertos, dos jogos digitais, dentre outras produções fundamentais para disseminar 
e expandir a infraestrutura tecnológica e a cultura de compartilhamento que originou a internet da qual tanto dependemos hoje.

As práticas de compartilhamento de informação e de saberes nos remete à Eric Raymond (2001), hacker e escritor, ao destacar que a cultura dos hackers é uma cultura de doação porque estes doam "seu tempo, sua criatividade e os resultados de sua habilidade."1 Dentre outros autores que estudaram e/ou conviveram com comunidades de hackers, destacamos Steven Levy (2010), Pekka Himanem (2001), que sistematizaram a ética dos hackers; Érica Mattos (2014), arquiteta urbanista, analisou o ethos hacker; Gabriella Coleman (2013), antropóloga, focalizou a cultura hacker; e nós, enfatizamos o jeito hacker de ser na Educação. Cada uma dessas escolhas analíticas traz uma semântica própria, amalgamada dentro de sua própria área de conhecimento e os estudos citados reconhecem que o universo dos hackers não é um todo de práticas harmônicas e de valores homogêneos, e ainda assim é possível identificar pontos de convergência a partir dos quais podemos traçar uma visão positiva desses sujeitos e entender a sua importância na atualidade.

Dentre características convergentes encontradas em estudos sobre a ética dos hackers, destacamos a paixão como mobilizadora das atitudes e do fazer; o próprio fazer, também chamado de atividade ou ativismo, pois é preciso colocar a mão da massa para tornar as aspirações reais; a criatividade em buscar um fazer autêntico, original e surpreendente; o valor social ou a reputação, representado pela valorização dos seus feitos junto à suas comunidades; o cuidado com o outro expresso nas contribuições e no apoio que se dá a outras pessoas e às comunidades; a abertura para compartilhar o que sabe e receber críticas ao que mostra; a estética representada pela beleza técnica e ética das soluções propostas; a liberdade de ser, agir e escolher o que fazer; a privacidade como condição necessária à liberdade e à experimentação que fundamenta o fazer. Dentre as características elencadas, destacamos especialmente a atividade, o fazer, a atitude, mas não de forma genérica, reprodutora ou impensada, o que nos remete ao conceito de hacking, tal como proposto por Érica Mattos (2014)

[...] hacking é uma prática multifacetada e mais do que estritamente relacionada a conhecimentos tecnológicos diz respeito a valores e uma maneira de agir. Tais valores podem ser interpretados e incorporados por pessoas das mais diversas áreas e assim assumir muitas formas também no contexto urbano. (MATTOS, 2014, p. 91).

A palavra hack era usada para se referir a atividades que testavam limites e habilidades em relação à imaginação e inteligência das pessoas. Considerava-se que um estudante estava fazendo

\footnotetext{
1 "By giving away your time, your creativity, and the results of your skill."
} 
um hacking quando se dedicava a investigar um assunto de interesse pessoal, ao invés de seguir o currículo acadêmico; quando alguém se lançava a explorar lugares de acesso restrito pelo campus universitário, ou quando estava fazendo algo considerado clandestino ou diferente das brincadeiras convencionais, ou seja, algo espetacular. Portanto, o hacking traz em si algo de criativo, divertido e subversivo. A imagem da pessoa que faz o hacking, ou seja, os hackers, origina-se desse repertório e ganha o mundo pelas ações desobedientes de jovens especialistas em programação de computadores, porque quando os computadores eram raros e caros, essas pessoas buscavam formas de torná-los acessíveis para si e para os outros. Sérgio Amadeu da Silveira (2010) ao discutir as relações entre o ciberativismo e a cultura hacker, identifica a influência da contracultura norteamericana na consolidação do chamado "hacktivismo". O ativismo hacker se expressa no trabalho colaborativo do movimento do software livre e segundo o autor, o pensamento hacker prega o compartilhamento de ideias e a emancipação individual pelo conhecimento. O estudo de Sérgio Amadeu da Silveira (2010) coloca em xeque a crença de que hackers são sujeitos individualistas, ao caracterizar a existência de um individualismo colaborativo que nasce da sociabilidade hacker em meios digitais. Muito além de lidar com saberes tecnológicos especializados, a atitude hacker surge de um pensar e um agir diferente, inovador e colaborativo que se expressa em diversos movimentos contra-hegemônicos notadamente mais acentuados com as tecnologias em rede a partir da expansão da internet.

Evidencia-se na história e no conjunto de características que elencamos, que a atitude hacker não se restringe a experts em software e pode ser encontrada em todos os níveis das ciências ou das artes. Como forma de expressão e ação sobre o mundo, o jeito hacker pode ser encontrado em profissionais de várias outras áreas como na medicina, nas artes, na arquitetura, na educação (RAYMOND, 2001; HIMANEN, 2001).

Paola Bernardi (2017)², educadora, questiona “E se criássemos um mundo de hackers?” em referência a uma palestra de um jovem canadense, Logan LaPlante, em 2013, quando ele diz que "Hackers são inovadores. Hackers são pessoas que desafiam e mudam os sistemas para fazê-los funcionar de um jeito diferente, fazê-los funcionar melhor." As ideias do hacking como um estilo de vida encontra eco no instrutor de yoga Renato Stefani, ao criar a plataforma chamada HackLife "para ajudar seres humanos a se integrarem, equilibrando os pilares corpo, mente e alma". ${ }^{3}$ Portanto, ser hacker tem a ver com se comprometer com a mudança e a melhoria do mundo e de si

\footnotetext{
${ }^{2}$ Disponível em: <http://ofuturodascoisas.com/e-se-criassemos-um-mundo-de-hackers>. Acesso 10 jun. 2019.

3 Disponível em: <http://falauniversidades.com.br/talvez-voce-precise-hackear-a-sua-rotina-conheca-o-hack-life/ e https://www.hacklife.co/sobre>. Acesso: 10 jun. 2019.
} 
mesmo. Como se vê, encontramos pessoas que se encantam com as potencialidades do "jeito hacker" principalmente fazendo referência ao pensar diferente, livre e inovador.

Portanto, mesmo que as referências às práticas hackers não ocupem a grande mídia com seus sentidos mais positivos, o imaginário social tem sido tomado por discursos e ações que incentivam o pensar criativo e inovador com tecnologias em diferentes dimensões da vida humana.

Para aglutinar os sentidos abarcados por esses autores e os sentidos observados empiricamente, adotamos o termo hackerismo como sinônimo de um conjunto complexo de orientações sócio-culturais influenciadas pela emergência hacker.

O termo hackerismo não é novo. Pekka Himanen (2001) utilizou a expressão "ética dos hackers" ao invés de hackerismo por considerar o primeiro mais abrangente que o puro hackerismo de computador, já que à época de suas reflexões, o termo era ligado especialmente aos jovens da área de computação. Já Renata Aspis (2012) escolheu ressignificar o léxico retirado de Pekka Himanem, atribuindo-lhe conotação mais ampla, com o significado de contra-conduta e inovação. Nas palavras dela trata-se de "não permitir a condução prévia das condutas, desviar da governamentalidade, e hackerismo como contracultura, revolver a cultura dada em busca de [algo diferente]" (ASPIS, 2012, p.172).

Portanto, mesmo que as referências às práticas hackers não ocupem a grande mídia com seus sentidos mais positivos, o imaginário social tem sido tomado por discursos e ações que incentivam o pensar criativo e inovador com tecnologias em diferentes dimensões da vida humana.

Para aglutinar os sentidos abarcados por esses autores e os sentidos observados empiricamente, compreendemos que a característica mais forte da ideia de hackerismo é sua inclinação para os sentidos de subversão, inovação e contra-hegemonia, principalmente do ponto de vista da liberdade individual, razão pela qual é comum a aproximação da lógica hacker com lutas libertárias e orientações políticas anticapitalismo. Porém, como nos mostra Himanen (2001) existem hackers capitalistas, mesmo reconhecendo que os significados originários das palavras capitalismo e hacker tenham surgido com sentidos opostos. No universo hacker - tanto quanto na humanidade nos deparamos com situações que não compreendemos ou com as quais não comungamos, mas isso não significa que elas não estejam lá ou que não determinem nossas falas e as ações.

O hackerismo, portanto, se relaciona a esse complexo contraditoriamente coerente que é o imaginário acerca do hacker contemporâneo, cujo ideário extrapola o mundo dos computadores e das tecnologias digitais, capilarizando-se entre áreas de conhecimento e segmentos sociais. E, como 
mostraremos a seguir, a atitude hacker não está unicamente atrás das telas dos computadores, o que nos abre brechas para extrapolar nossas análises para o campo da educação.

\section{HACKERISMO ENTRE AS TELAS E AS JANELAS}

Forçosamente é preciso assumir que, para a maioria de nós, o momento contemporâneo não abre muitos espaços para a expressão de criatividades subversivas, especialmente se considerarmos a conformação do mundo do trabalho e da educação no sistema econômico capitalista, ainda muito espelhado na divisão de classes e na fragmentação da produção instaurada com a revolução industrial. Ademais, as influências do sistema econômico e as desigualdades sociais se fazem sentir também no mundo digital, criando falsas inclusões, reconfigurando exclusões antigas e trazendo novas assimetrias.

Nesse cenário constituído de tensionamentos diversos, observamos a emergência de movimentos sociais que se colocam na contramão da cultura hegemônica, propondo formas diferenciadas de ativismo, de produção cultural e de sociabilidade que estão além do ciberespaço e da cibercultura, e ao mesmo tempo, relacionada a eles. Esses movimentos tendem a ser descentralizados e informais e originando laboratórios experimentais (FONSECA, 2011), ou laboratórios tecnológicos experimentais (BRAZILEIRO, 2015) fortalecendo essas tendências contra-hegemônicas questionadoras do status quo desigual e consumista, incluindo a busca de outras sociabilidades através da criação de espaços seguros, com apoio e segurança emocional, estruturados para compartilhamento de valores comuns e construção da autonomia de seus integrantes, dentro de um sentimento de comunidade. Voltando um pouco no tempo, isso aconteceu, por exemplo, com um grupo de hackers na Alemanha, quando, durante uma conferência tecnológica - the Computer Conference (CoCon) - realizada em meio às mudanças políticas que levaram à queda do muro de Berlim, foram sendo forjadas as bases para um espaço que abrigasse os hackers alemães com privacidade e liberdade. O Caos Club Computer (CCC Berlim) foi fundado em 12 de setembro de 1981 e defendendo que "a descentralização e a falta de hierarquia podem ser a força que faz o clube resistir a todas as tendências de se dissolver e se desintegrar, sendo ainda uma comunidade próspera e crescente de indivíduos e que regularmente consegue se reinventar" (ASTERA e PETTI, 2008, p. 06). Com essas premissas, foi criado o primeiro Hackerspace do mundo. A proposta do CCC foi se disseminando pelo território alemão e motivando a outros grupos, inclusive, grandes hackerspaces estadunidenses como o Noisebridge em São Francisco,/Califórnia o NYC Resistor em Nova York, também inspiradores de mais espaços desse tipo pelo mundo. 
No Brasil, entre tantos outros pioneiros exemplos, citamos o MetaReciclagem, um dos precursores da defesa da metareciclagem tecnológica e da engenharia reversa como forma de aprendizagem e de sustentabilidade econômica e social no Brasil. O movimento envolveu ativistas, acadêmicos, comunicadores, programadores e pessoas em torno de projetos nas áreas de educação, arte, tecnologia. Sua criação data de 2002, a partir do Projeto Metá:Fora, uma lista de discussão sobre comunicação, internet, filosofia e cibercultura, constituindo-se como um projeto aberto, ancorado nos princípios do software livre (DIAMANTAS, 2013).

O que difere hackerspaces de outros laboratórios tecnológicos experimentais pautados na lógica do faça-você-mesmo é o fato de se nortearem por princípios da cultura hacker e na filosofia do software livre, aproximando desafios e saberes globais com respostas e soluções locais.

Conforme registros no site hackerspaces.org em maio de 2019, existiam 2.327 hackerspaces pelo mundo, sendo 1.417 deles em atividade. No Brasil, na mesma época, estavam listados 54. Não é possível registrar com exatidão quantos espaços hackers existem pelo território brasileiro, afinal existem laboratórios experimentais (FONSECA, 2011) que se configuram como hackerspaces por se inspirarem no ideário hacker sem, no entanto, participarem diretamente desse movimento e portanto, não se denominarem como tal. Do mesmo modo, existem agrupamentos que assim se auto intitulam, mas são questionados por uma parte da comunidade, pois suas condutas não condizem com os princípios hackersistas. De modo geral, os espaços hackers tem se ampliado e estes assumem formatos diversificados, dentre os quais encontramos iniciativas de grupos de amigos, parcerias com instituições públicas ou privadas, com instituições de ensino, coworkings e outras formas organizativas, mas eles têm em comum, em sua maioria, a organização autogestionárias, sendo mantido pelos membros associados voluntariamente através do pagamento de mensalidades e doações.

Boa parte da organização desses espaços se dá através das redes digitais, com mobilizações para criação e manutenção desses espaços. As redes sociais, blogs, páginas web, são caminhos de comunicação e divulgação de intenções e de encontros entre participantes e interessados. No entanto, um hackerspace é vivido na presencialidade do espaço que ocupa e não apenas em redes virtuais, mesmo que essas tenham enorme importância para a organização e transparência das atividades realizadas. Hackerspaces nascem da convergência entre pessoas diferentes com interesses em comum e das listas de discussão, grupos online ou wikis são os melhores lugares para juntar essas pessoas, independentemente das barreiras físicas. Portanto, as práticas hackers em hackerspaces transitam pelo comunicar-se e fazer-se conhecer em duas dimensões implicadas: o presencial e o digital, esferas que trazem desafios específicos, que podem ser analisados pelo viés 
das práticas educativas pois destas depende sobremaneira a existência do local físico e a continuidade do sonho hacker contemporâneo. Hackerspaces não são exclusivos de ambientes urbanos e superconectados. Diferentemente disso, surgem do encontro virtual e materializado entre pessoas que possuem conhecimentos especializados e posicionamentos ativistas onde quer que elas estejam.

Diante disso é possível compreender a emergência dos espaços hackers como uma necessidade não apenas das comunidades hackers, mas de grupos humanos, de modo mais amplo. A história do movimento de criação dos hackerspaces aponta para a busca de espaços coletivos e compartilhados, capazes de acolher seus frequentadores com privacidade, segurança e, ao mesmo tempo, com liberdade e abertura onde a aprendizagem é tão essencial quanto o convívio entre as pessoas hackeristas.

Durante os anos de 2015 a 2018, desenvolvemos um estudo empírico (MENEZES, 2018) através do qual entramos em contato com 20 hackerspaces através de seus canais de comunicação digitais. Buscamos conhecer a história, o funcionamento e as práticas neles realizadas. Desses, obtivemos resposta de 12 por meio de entrevistas via rede. E, tendo como foco caracterizar a pedagogia existente em hackerspaces brasileiros, ampliamos o levantamento de informações com o uso de questionário online, o que trouxe a representação de outros 10 espaços, totalizando 22 grupos representados.

A partir de respostas espontâneas em um dos campos do questionário, mapeamos as motivações daqueles participantes para aderirem a esse tipo de espaço, sendo a principais 1) defesa da filosofia e da cultura hacker, 2) oportunidades de aprendizagem, 3) sociabilidade e encontro com amigos, 4) trocas de conhecimento e 5) desejo de ajudar e de participar. Como se nota, as motivações dos participantes coincidem com as reflexões acerca do ideário hacker da colaboração e da aprendizagem pela troca de conhecimentos.

Diante das demandas sociais impostas de aprender cada vez mais com e sobre tecnologias, enquanto o mundo do trabalho se reconfigura para abarcar novas funções e perfis mais criativos e na medida em que os problemas causados pelo acelerado desenvolvimento tecnológico se agravam, a visão do espaço hacker como um local de aprender de forma diferenciada se fortalece. Quando questionamos sobre os momentos em que mais se aprende em um espaço hacker, as respostas encontradas dão maior ênfase para a realização de oficinas, projetos e conversas. Como características dessas atividades, os participantes da pesquisa chamaram atenção para a ludicidade, no sentido de haver uma ambiência que estimule a troca de conhecimento aberta e desafiadora ao 
invés de posturas passivas; destacaram também a responsabilização frente às atividades propostas e a liberdade de escolha em realizá-las ou não. Apesar de parecer contraditório, a responsabilidade e a liberdade de escolha colocam em evidência a formação de grupos de interesse necessários à realização de qualquer empreitada dentro de um espaço hacker. Ninguém é obrigado a fazê-lo, mas se alguém de compromete, precisa assumir o compromisso junto aos outros.

No que diz respeito aos conteúdos aprendidos, destacamos que os respondentes não se referiram especificamente a aprendizagens técnicas, pois citaram conteúdos ligadas à filosofia, sociologia, e o desenvolvimento da sua sociabilidade, contudo, quando perguntados sobre o que foi aprendido ou ensinado no hackerspace, os conhecimentos específicos das áreas tecnológicas são significativamente mais abundantes, mostrando que estar em um desses lugares é estar aberto para aprender mais sobre tecnologias.

A escolha de se engajar em um hackerspace e nele permanecer não é uma escolha simples pois muitos são os desafios encarados pelos integrantes: é preciso assumir burocracias para o levantamento de fundos para pagamentos de despesas, manter a limpeza, garantir o uso do espaço com liberdade e organização, é preciso ocupá-lo e ter transparência na arrecadação e nos gastos. E tudo isso é feito pelos membros participantes, usualmente de forma voluntária. Nesse cenário, os embates diante de questões básicas, como por exemplo, lavar pratos ou manter um banheiro limpo, podem ser motivos de grande desgaste dentro do grupo. Essa é mais uma característica da educação que ocorre nesses espaços, pois a despeito dos problemas e desafios de manutenção, insiste-se que o aprendizado é grande e diversificado.

Ao analisarmos alguns desafios apresentados pelos participantes no desenvolvimento de atividades pedagógicas em suas sedes, ficou evidente o quanto essas limitações espelham e reverberam na vida e manutenção do espaço. O primeiro desafio, a dispersão, se dá de diferentes formas:

a) Dispersão de objetos: os artefatos materiais de um hackerspace são de uso coletivo. Quando não há uma forma de organização desses artefatos que seja compreensível aos integrantes, as atividades a serem realizadas são prejudicadas;

b) Dispersão de temas de interesse: a diversidade constituinte do espaço se revela nos interesses de seus integrantes, de tal modo, é comum que em um mesmo encontro ocorram debates com assuntos paralelos ao que seria considerado o tema central. Muitas vezes, as conversas paralelas surgidas a partir de dúvidas e desejos imediatos dificultam o direcionamento de atividades práticas que poderiam ser de interesse comum dos participantes; 
c) Dispersão de abordagens: essa dispersão pode ser tomada como desorganização de métodos ou estratégias. Acontece quando se escolhe realizar alguma atividade sem um planejamento anterior, ou quando mais de um encontro com objetivos diferentes acontece no mesmo espaço. A circulação de muitas pessoas envolvidas com atividades diferentes pode causar uma situação caótica na qual a concentração e foco necessários para determinados tipos de atividades ficam comprometidos. Quando há atividades planejadas previamente, a dispersão pode advir da inexperiência dos orientadores ao não conseguirem envolver os participantes, abrindo espaço para que outras atividades paralelas surjam interferindo no que já estava sendo feito.

d) Dispersão de pessoas: a falta de assiduidade nos encontros presenciais (nos quais estão também as reuniões administrativas) tendem a ser desmotivantes. Uma das causas da dispersão de pessoas é a escassez de tempo dedicado às atividades no hackerspace. Por se tratar de um engajamento voluntário, é comum que os integrantes tenham outras prioridades, dispondo de pouco tempo para planejar os encontros temáticos, os projetos ou até, dar continuidade a eles.

Diante disso, aprender nesses espaços pode ser lúdico e interessante, mas isso não significa que seja fácil. As limitações infraestruturais e financeiras prejudicam a manutenção da sede, e o desenvolvimento de projetos que exigem instrumentos ou materiais que não são conseguidos por doações. Além disso, com recurso financeiro reduzido é difícil imprimir ao espaço físico um design e decoração mais estimulante e inclusivo para todos os participantes.

Quando se fala em inclusão, a discussão não se resume aos aspectos físicos. Ela passa pelas relações pessoais que são estabelecidas entre os participantes. Visões preconceituosas, o desconhecimento do ideário hacker e das regras implícitas do local, o desrespeito a outros participantes, o desinteresse em interagir com outras pessoas e não compartilhar ideias, buscando apenas receber e nunca trocar conhecimentos, são pontos geradores de conflitos. Pessoas que agem com petulância, respaldando-se em certificações, títulos acadêmicos ou diplomas para se posicionar perante os demais são vistas com desconfiança. E quando situações de conflito se estabelecem nem sempre ocorre a mediação necessária para promover acolhimento podendo gerar afastamentos, desestímulos e ausências que colocam em risco o futuro do espaço. Diante disso, a relação entre educação e existência do hackerspace é muito forte, pois é desse processo de diálogo, acolhimento, inclusão, participação, engajamento que ele se mantém vivo. 


\section{PRÁTICAS EDUCATIVAS E ENGAJAMENTOS REAIS}

As práticas educativas realizadas em hackerspaces são inseparáveis do hackerismo e portanto, sinalizam junções que, em um primeiro olhar, podem ser consideradas divergentes como a privacidade e abertura, compartilhamento e competição, diversão e trabalho, aprender junto e autodidatismo através de práticas mão-na-massa, na qual o fazer é o promotor do mérito e do reconhecimento social. As práticas educativas são abrangentes e envolvem ações intencionais, mesmo que sejam intuitivas, elas são sempre mediadas pela linguagem. Nessa perspectiva, as práticas educativas nos hackerspaces brasileiros podem ser identificadas em diferentes momentos e locais que não são necessariamente direcionados pelo e para o ensino. Como exemplo, as reuniões administrativas, os debates em listas de discussão online, as festas realizadas dentro dos espaços. Todos esses, momentos nos quais não se tem como centralidade o aprender e o ensinar, mas se tem como foco a organização, manutenção ou a convivência no espaço tendem a ser educativos, pois neles são compartilhados valores, implícita ou explicitamente, através de acordos e decisões coletivas que condicionam a conduta dos membros. A possibilidade de aprender em momentos como reuniões administrativas, conversas, discussões, eventos festivos, encontros virtuais são sinalizadoras da perspectiva educativa em hackerspaces geralmente orientadas para o estar junto, o estar com.

A organização por projetos é o motor das atividades realizadas em um espaço hacker, mesmo que esses projetos não sejam sistematizados claramente. Os projetos estruturam as práticas educativas desses espaços. Um projeto pode significar algo como um desejo, uma intenção, algo que se pretende para o futuro, mas do ponto de vista organizacional para alcançar resultados, exige propósitos e fins. Segundo John Dewey (1979) um propósito nasce de impulso e converte-se em desejo. Estes se diferenciam porque um propósito é um fim em vista, e portanto, requer observação das condições objetivas e das circunstâncias para que possa ser empreendido. Um propósito implica também na significação do que é observado, e a significação está ligada a experiências anteriores e, por fim, um propósito é formado pelo julgamento sobre a situação presente. Em síntese, a formação de um propósito é uma operação intelectual complexa porque articula impulso e o desejo com a observação, significação e julgamento no sentido de gerar uma possibilidade de ação real ou seja, com objetivos alcançáveis transladando "para um plano ou método de ação, baseado na previsão das consequências de agir nas condições observadas de um certo modo.” (DEWEY, 1979, p.68)

A inconclusão de uma ideia proposta não significa necessariamente seu esquecimento. A maior parte das ideias e projetos de hackerspaces constam publicamente em seus sites. Dessas situações, evidenciam-se alguns dos preceitos antes discutidos: 1) a cultura hacker é uma cultura de 
doação, nesse caso, de doação de ideias, de tempo. 2) É também uma cultura façocrata, é o reconhecimento de quem coloca a mão na massa. Não se delega trabalho a outrem. 3) É uma cultura colaborativa, na qual qualquer interessado pode contribuir mesmo que não tenha muito conhecimento na área e, portanto, 4) é uma cultura de compartilhamento pois aqueles que sabem um pouco mais trocam conhecimento com aqueles que sabem menos acerca de certo assunto.

É importante a presença, a participação, a implicação, o envolvimento com o espaço hacker para que ele tenha uma continuidade e um sentido para seus participantes e entusiastas. Os projetos nos mostram que a aprendizagem nem sempre está no foco da organização dos grupos e mesmo que a aprendizagem não seja o objetivo dos projetos encampados, quando há engajamento na proposta, um impulso que se tornou desejo tende a transformar-se propósito, gerando processos que modificam o espaço e potencialmente modificam as pessoas envolvidas, através de seus aprendizados. Por isso a aprendizagem ali surge, também, como uma reverberação de vivências engajadas.

Daí afirmarmos que nesses espaços não se trata de só aprender, porque a própria ideia de existência do espaço hacker já é um motivador. É como um sonho que depende de muitas mentes e muitas mãos para tornar-se e manter-se real. Um sonho que para realizar-se precisa de engajamento.

Colocamos em relevo que o ato de engajar-se é uma atitude ativa, não há engajamento passivo, portanto, engajar-se exige participação. A participação nesse sentido, não é algo dado, é uma construção individual e também social que se manifesta de várias formas. O menor grau de participação consiste em estar informado e o maior grau é a autogestão (BORDENAVE, 1989). Rogério Córdova (2004), fala de participação efetiva como aquela que se constrói com a autonomia nos planos individual e coletivo. No plano individual, a autonomia se dá pela tomada de consciência diante do discurso do outro sobre si. No plano coletivo, a autonomia advém da instauração de uma outra maneira de nos relacionarmos com o que está instituído, ou seja, com as instituições. Na obra freireana (1987) a participação efetiva é o próprio engajamento e este engajamento tem a ver com a busca de transformação social, mas que depende da transformação de si mesmo a partir do lugar que ocupa. Assim, o engajamento quando vinculado a um ato de conhecimento seria também um ato criador, porque o próprio ato de conhecer é potencialmente criador. Portanto, o engajamento aqui é tomado como ato político e portanto, nunca é neutro.

Apoiando-se em Sartre, Cunha (2003) afirma que "engajamento corresponde à atitude ética e política autoreferente de fazer escolhas absolutamente livres com o intuito de criar a si mesmo e 
reinventar o mundo". Diante disso, é correto afirmar que o engajar-se é um ato político tanto quando construção de identidade, de autoconhecimento, de reconhecimento social.

\section{OS QUATRO TIPOS DE ENGAJAMENTO EM HACKERSPACES BRASILEIROS}

Conforme explicitamos anteriormente a ideia de engajamento se opõe à pseudoparticipação (FREIRE, 1987) e se sobrepõe às noções de fazer parte, tomar parte e ter parte para assumir o necessário equilíbrio entre a participação afetiva e instrumental (BORDENAVE, 1989) e direcionando essa ação de participar efetivamente para si mesmo e para angariar a participação de outras pessoas. $\mathrm{O}$ engajamento é um tipo de participação que se dedica a colaborar para que outras pessoas participem ou se engajem também. Por isso, afirmamos que todo engajamento exige participação, mas nem toda participação é engajamento. Diante disso, sistematizamos quatro tipos de engajamentos relacionados à vivência em hackerspaces brasileiros.

\section{Engajamento técnico}

O conhecimento técnico compartilhado em hackerspaces é de interesse de significativa parte de seus membros e frequentadores. $\mathrm{O}$ que pode ser corroborado pela ênfase em encontros práticos com metodologias ativas, tais como oficinas, e pelo caráter dos projetos e grupos de estudos práticos em áreas com conteúdos técnicos específicos, como eletrônica, robótica e programação. $\mathrm{O}$ sentido da palavra técnica não se coloca aqui como uma redução do saber a algo eminentemente irrefletido ou reprodutível, mas como dimensão do conhecimento humano necessário para se modificar a natureza, alcançar objetivos específicos, produzir coisas e realizar sonhos que em determinadas épocas seriam considerados impossíveis. O interesse técnico não se limita ao aprendizado e reprodução de técnicas já existentes e não se contenta com saídas pouco criativas. A essência do hacking está no encontro de uma ideia/solução com as técnicas empregadas para realizar o feito, afinal, um hacker é reconhecido também pela virtuosidade daquilo que faz. Para se desenvolver novas técnicas, o acesso a ferramentas é tão importante quanto acesso a informações necessárias para produção de conhecimento, mas nem todo espaço hacker tem infraestrutura material suficiente para produções técnicas inovadoras. Para lidar com escassez de ferramentas e de infraestrutura, é comum que os integrantes doem, emprestem, e compartilhem seus instrumentos e ferramentas próprias. Tal situação nos remete às reflexões de Milton Santos, ao afirmar que a opulência dos lugares não advém de sua densidade técnica, mas de sua densidade humana (SANTOS, 1996, p. 37), e essa densidade humana se expressa nas vivências dentro do espaço hacker e se concretiza quando há proximidade de interesses e valores, e partilha da cultura hacker. 


\section{Engajamento afetivo}

Pelos relatos e respostas analisadas, os fundadores de hackerspaces o fizeram na companhia de amigos. É comum a esses integrantes se vincularem pela indicação de amigos e se engajarem no espaço motivados pelas amizades. A relação de afeto entre as pessoas que frequentam o espaço é um ponto de grande relevância no engajamento, inclusive quando se trata de pessoas cujos interesses técnicos ou o conhecimento do ideário hacker não são proeminentes. As relações afetivas entre as pessoas são fator de convergência e participação em espaços hackers, mas essa afetividade não se resume às relação entre as pessoas, pois também se direciona para as práticas vivenciadas no local. Dentre as outras razões informadas pelos participantes para se engajar, estão a crença no ideário hacker, o desejo de aprender e ensinar. Ao conviver e pesquisar sobre como os saberes são desenvolvidos nas práticas de participantes do MateHackers (Porto Alegre/RS), Cecília Burtet (2014), recorre ao conceito de teleoafetividade das práticas com base em T. R. Schatzk (2001). A teleoafetividade é, segundo Schatzk (2001) um fenômeno mental, uma mistura de teleologia e afetividade. A teleologia é compreendida como orientações para fins específicos, enquanto a afetividade é interpretada como as coisas que importam para a pessoa. Uma pessoa tende a fazer coisas que façam sentido para si mesma, coisas nas quais vê importância "dadas suas crenças, esperanças e expectativas, e suas emoções e estados de espírito" (SCHATZK, 2001, p. 60). O afeto, popularmente tomado como sentimento de bem querer, na verdade trata de uma gama de sentimentos e emoções humanas mais complexas, operando na esfera da subjetividade que muitas vezes é desconsiderada ou tomada como algo menor nos discursos dualistas da racionalidade. Mas a afetividade humana é uma das funções psíquicas superiores, aquelas que se caracterizam pela elaboração de signos e símbolos, como o pensamento lógico, a memória consciente e a vontade (PRESTES, 2010, p. 36; LOOS, SANT'ANA, 2007). No universo hacker, a afetividade vem expressa como paixão, diversão, desejo, curiosidade e sociabilidade palavras comuns nos estudos que sistematizam a cultura e a ética dos hacker. Mesmo sendo estruturante, o engajamento afetivo por si somente não é suficiente para compor a pedagogia hacker.

\section{Engajamento ideário}

O engajamento em hackerspaces, bem como os processos educativos realizados neles, são constituídos por um ideário que aqui é compreendido como o conjunto das ideias mais relevantes e singulares da filosofia/cultura/ideologia hacker no seu sentido mais positivo que, no imaginário social, destacam-se como algo a ser incentivado e disseminado. As falas dos participantes da pesquisa que deu origem a esse texto evocam esse conjunto de ideias, sendo que a oportunidade de vivenciar e partilhá-las é um fator de motivação para o engajamento. O engajamento ideário a partir 
do que foi observado nos hackerspaces brasileiros tem como eixos centrais a visão desse espaço como local de experimentação e aprendizagem, de inovação e subversão, de produção e compartilhamento de conhecimentos, de sociabilidade, de diversão. Essa visão positiva da função social dos espaços hackers contribui para que haja muito mais apoiadores virtuais - em redes sociais, por exemplo - que membros efetivos.

\section{Engajamento ativista}

A presença dos participantes no espaço hacker é definidora do sucesso daquele espaço, pois é condição para sua existência. $\mathrm{O}$ ativismo que identificamos não se restringe à atividades virtuais e nem às comunidades hackers. $\mathrm{O}$ ativismo preocupado com a realidade envolvente é encontrado em outros grupos hackers, evidenciando que esse ativismo se dá no engajamento com a vida interna da sede através de projetos colaborativos coletivos ou individuais que projetam a filosofia hacker e o próprio espaço para além de si mesmo. Isso exige claramente levantar do sofá de casa e ir para o sofá do hackerspace. Isso se justifica exatamente porque a existência e manutenção de espaços autogestionários de produção e compartilhamento de conhecimento dependem de dois tipos de presença: no espaço físico e no ciberespaço, afinal esses são locais de convergência para engajamento nessas duas frentes. Como explicitado anteriormente, ficou muito forte no decorrer da pesquisa o quanto é importante a presença, a participação, a implicação, o envolvimento com o espaço hacker para que ele tenha uma continuidade e um sentido para seus participantes ou para entusiastas.

Não há como separar as práticas educativas da vida do hackerspace, pois elas estão imbricadas em um processo de acolhimento e inclusão que exige abertura e proatividade dos envolvidos. A construção do hackerismo como filosofia de vida, emerge nas relações de pertencimento com o grupo e isso não se dá sem paixão, sem afetividade. Percebemos que esses aspectos todos podem ser congregados em uma única palavra, e por isso, a resgatamos: engajamento. $\mathrm{O}$ engajamento pressupõe uma ação do sujeito sobre si que provoca ou influência os outros, logo, tem uma dimensão individual, comunitária e coletiva. Os membros ativistas engajados demonstravam maior disposição em assumir tarefas nos hackerspaces, não sendo movidos apenas pela afetividade, mas também pelo compromisso ativista de promoção do espaço, zelando pelo nome e pela identidade ali construída coletivamente. É a vivência ativa situada no espaço hacker, na afetividade, no ideário e no domínio técnico ali emergente que irá condicionar as aprendizagens ou a não aprendizagens e consequentemente, as identidades de seus participantes e a existência do espaço. Isto é, além do simples estar presente, a convivência engajada. É também o compartilhar através do aprender e do ensinar. É estar junto, olho no olho, colaborando. No contexto humano, 
isso tem sido especialmente desafiador para muitas pessoas que, quando reunidas nesses espaços, são iguais na diferença. Há aquelas pessoas tímidas, nervosas e briguentas, há outras que são descoladas, curiosas, faladoras, que fazem perguntas o tempo todo e atrapalham quem está estudando e também aquelas que dizem não saber nada e por isso não deixam ninguém em paz. Nessa convivência, os viventes são quem são, e ao mesmo tempo se modificam tornando-se diferentes aos olhos de si e dos outros. Quem se sente preparado, ensina. Quem está interessado, aprende. O convívio não é imposto. Não é obrigatório, mas é indispensável. Daí a convivência é também lúdica. Não apenas porque é brincante, mas porque é afetiva, desafiadora e arriscadamente efêmera.

Com isso, a pedagogia hacker integra a educação com o fazer lúdico, no seu sentido mais amplo e completo. Portanto não é apenas produção, não é apenas brincadeira e nem apenas competição. É uma convergência de tudo isso acrescida de princípios de abertura e compartilhamento, além de uma forte exigência de autonomia e compromisso mesmo diante de esvaziamento e solidão. A pedagogia hacker é exigente de posturas ativas tanto dos aprendizes quanto dos mestres, porque a função de ensinar e o desejo de aprender se tornam funções intercambiáveis. E no caso de hackerspaces, tudo isso pode ser fugaz. Superar a fugacidade depende que a convivência entre os integrantes seja amalgamada no sentimento de pertença. $\mathrm{O}$ hackerspace está na pessoa mesmo quando a pessoa já não está. Ela se sente parte, é parte e é reconhecida por isso - essa é a convivência engajada que leva à partilha da cultura do espaço, às suas práticas educativas.

\section{A PIRÂMIIDE DA PEDAGOGIA HACKER}

Podemos, assim, em busca de uma síntese provisória, pensar na existência de uma Pedagogia Hacker. A força motriz desta proposta de Pedagogia Hacker está no engajamento, mas não como um conceito genérico. Trata-se de um conjunto de engajamentos com inclinações e motivações específicas fortalecidas pela convivência. No caso dos hackerspaces, os engajamentos técnico, afetivo, ativista e ideário interconectam-se como faces de uma pirâmide: a pirâmide da pedagogia hacker $(\mathrm{P} 2 \mathrm{H})$. Para que o sonho de um grupo de pessoas se torne uma realidade do coletivo, é preciso investir nos seus engajamentos de forma consciente e intencional e é isso que a pedagogia faz. Portanto, a pedagogia dos hackerspaces depara-se com uma dupla missão: produzir aprendizados demandados por seus participantes e educá-los para que o espaço físico em si não pereça. 
A pirâmide da pedagogia hacker nos permite uma síntese para refletirmos sobre a educação de forma mais ampla, afinal, questões importantes se colocam quando aceitamos que para se educar é preciso, no mínimo, abarcar as afetividades, os ativismos, os ideais e as técnicas, tal como as faces da P2H. A investigação contribuiu para repensarmos a educação e os processos educativos de forma originária, na medida em que compreendermos profundamente os princípios que regem a organização de grupos que levam seus ideais para além do ciberespaço, se organizando para criticar valores hegemônicos em seus aspectos éticos, políticos e econômicos. Ao estudar as posturas de participantes engajados, notamos que há por trás de seu modo organizativo algo de autoformação e de educação em rede, que reconecta os indivíduos em torno de objetivos comuns, sem massacrar as individualidades.

Não há aqui a defesa do hackerismo como alternativa redentora para a educação na contemporaneidade. Conforme explicitado anteriormente, as contradições são tão inerentes à cultura hacker que dentre seus integrantes também encontramos reverberações das mazelas sócioeconômicas identificadas em outros espaços e expressões de preconceito e intolerância sobre as quais escolhemos não no debruçar nos limites dessa investigação. Nossa decisão se justifica porque tais situações não são a tônica do movimento analisado e cada espaço hacker responde de seu próprio seu jeito a cada uma delas, seja através de seus indivíduos ou de seus coletivos. 


\section{REFERÊNCIAS}

ASPIS, Renata Lima. Hackerismo como resistência política. In: AMARAL, S. Ferreira; PRETTO, Nelson L. (Org.). Ética, hacker e a educação. Campinas: FE/UNICAMP, 2009.

BORDENAVE, Juan E. Diaz. O que é participação. São Paulo: Brasiliense, 1989.

BRAZILEIRO, Ricardo. Espaço, território e inovação tecnológica nos CEUs. LABCEUS. Laboratórios de Cidades Sensitivas. 2015. Disponível em: <http://culturadigital.br/labceus/2015/05/19/espaco-territorio-e-inovacao-tecnologicanos-ceus/>. Acesso em: 05/01/2018.

BURTET, Cecília Gehardt. Os saberes desenvolvidos nas praticas em um hackerspace de Porto Alegre. Dissertação (Mestrado em Administração) - . Programa de Pós-graduação, Universidade Federal do Rio Grande do Sul, Escola de Administração, , Porto Alegre, 2014.

COLEMAN, Gabriella E. Coding freedom: the ethics and aesthetics of hacking. New Jersey, USA: Princeton: Princeton University Press, [s.d.].

CÓRDOVA, Rogério de Andrade. Instituição, educação e autonomia na obra de Cornelius Castoriais. Brasília: Plano Editora, 2004. 130 p.

CUNHA, Gilson A. Ética nas proposições pedagógicas de Paulo Freire: o engajamento ético-pedagógico do educador. 2003. Dissertação (Mestrado m Educação) - Centro De Educação Universidade Federal de Pernambuco, Recife, 2003.

DEWEY, John. Educação e Experiência. São Paulo: Companhia Editora Nacional, 1979.

DIAMANTAS, Hernani. Zonas de colaboração: conversas da MetaReciclagem. Senac: São Paulo, 2013.

FONSECA, Felipe. Laboratórios do Pós-digital. 2011. Disponível em: <http://efeefe.no-ip.org/sites/efeefe.noip.org/files/lpd tela.pdf>. Acesso em: 12 abr. 2015.

FREIRE, Paulo. Pedagogia do Oprimido. Rio de Janeiro: Paz e Terra, 1987.

HIMANEN, Pekka. A ética dos hackers e o espírito da era da informação. Trad.: Fernanda Wolf. Rio de Janeiro: Campus, 2001. 200p.

LEVY, Steven. Hackers: heroes of the computer revolution. [s.1.]: O’Reilly Media, 2010.

MATTOS, Erica Azevedo da Costa e. Ethos hacker e hackerspaces: práticas e processos de aprendizagem, criação e intervenção. Dissertação de mestrado. Universidade Federal de Santa Catarina. Florianópolis, SC, 2014.

MENEZES, Karina Moreira. P2H: pirâmide da pedagogia hacker : [vivências do (in)possível] / Tese (doutorado em Educação) - Faculdade de Educação, Universidade Federal da Bahia. Salvador, 2018.

LOOS, H.; SANT'ANA, R. S. Cognição, afeto e desenvolvimento humano: a emoção de viver e a razão de existir. Educar, Curitiba, n. 30. Editora UFPR, 2007.

PRESTES, Zóia. Quando não é quase a mesma coisa: Análise de traduções de Lev Semionovitch Vigotski no Brasil : Repercussões no campo educacional. Tese. UNB: Brasília, 2010.

RAYMOND, Eric Steven. How to become a hacker. 2001. Disponível em: <http://catb.org/ esr/faqs/hackerhowto.html>. Acesso em: 02 mar. 2015.

SANTOS, Milton. O lugar encontrando o futuro. Revista de Urbanismo e Arquitetura, vol 04. n.1, 1996.

SEARA. Simone. Hackers: a visão da imprensa brasileira sobre o underground na internet. Dissertação. FACOM: UFBA, 2001.

SILVEIRA, Sérgio Amadeu da. Ciberativismo, cultura hacker e o individualismo colaborativo. Revista USP, Brasil, n. 86, p. 28-39, aug. 2010. ISSN 2316-9036. Disponível em: <http://www.revistas.usp.br/revusp/article/view/13811>. Acesso em: 25 nov. 2017. doi:http://dx.doi.org/10.11606/issn.2316-9036.v0i86p28-39. 


\section{RESUMO}

O artigo parte da identificação e análise sobre a origem e o funcionamento dos espaços hacker no Brasil com o objetivo de compreender seu funcionamento e as práticas de seus participantes para buscar compreender a dimensão educativa desses espaços. Um pesquisa de campo analisou, a partir de entrevistas, visitas aos espaços físicos e nas redes, como esses espaços estão estruturados e funcionam. Como resultado, identificase que eles possuem uma Pedagogia própria, estruturada em engajamentos, através dos quais esses espaços físicos são criados e ampliados. Conclui-se definindo o conceito de Pirâmide da Pedagogia Hacker em Hackerspaces (P2H), cuja faces são engajamentos interconectados - técnico, afetivo, ativista e ideário fortalecidos pela convivência. A pedagogia nos hackerspaces tem a dupla missão de produzir aprendizados e garantir que o espaço físico não pereça.

Palavras-chave: Hacker; Educação hacker; Educação.

\section{PYRAMID OF HACKER PEDAGOGY: FROM COLLECTIVE DREAMS TO REAL ENGAGEMENTS}

\section{ABSTRACT}

The paper starts with the identification and analysis of the origin and functioning of the hackerspaces in Brazil to understand the operation and practices of its participants to identify the educational dimension of these spaces. Survey analyses, from interviews, visits to physical spaces, and webpages, how these spaces are structured and work. As a result, we identified that they have a specal Pedagogy, structured in engagements, through which these physical spaces created and enlarged. It concludes by defining the concept Pyramid of Hacker Pedagogy in Hackerspaces (P2H), whose faces are interconnected engagements - technical, affective, activist and ideological - strengthened by coexistence. Hacking pedagogy has the dual mission of producing learning and ensuring that physical space does not perish.

Key word: Hacker Education; Educational Tecnhology; Education.

\section{PIRÁMIDE DE LA PEDAGOGÍA HACKER: DE SUEÑOS COLECTIVOS A COMPROMISOS REALES}

\section{RESUMEN}

El artículo parte de la identificación y análisis sobre el origen y el funcionamiento de los espacios hacker en Brasil con el objetivo de comprender su funcionamiento y las prácticas de sus participantes para comprender la dimensión educativa de esos espacios. Una encuesta de campo analizó, a partir de entrevistas, visitas a los espacios físicos y en las redes, como esos espacios están estructurados y funcionan. Como resultado, se identifica que ellos poseen una pedagogía propia, estructurada en compromisos, a través de los cuales esos espacios físicos son creados y ampliados.

Concluye definiendo el concepto de la Pirámide de Pedagogía Hacker en Hackerspaces, cuyos rostros son compromisos interconectados (técnicos, afectivos, activistas e ideales) fortalecidos por la coexistencia. La pedagogía Hackear tiene la doble misión de producir aprendizaje y garantizar que el espacio físico no perece.

Palavras clave: Educación Hacker; Tecnología Educacional; Educación 